Pacific Northwest

National Laboratory

Operated by Battelle for the

US. Department of Energy

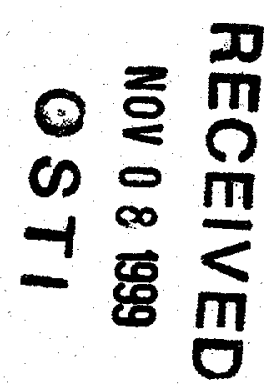

\title{
Effects of Crust Ingestion on Mixer Pump Performance in Tank 241-SY-101: Workshop Results
}
P. A. Meyer
C. W. Stewart
C. E. Brennen

September 1999

Prepared for the U.S. Department of Energy under Contract DE-AC06-76RLO 1830 


\title{
DISCLAIMER
}

This report was prepared as an account of work sponsored by an agency of the United States Government. Neither the United States Government nor any agency thereof, nor Battelle Memorial Institute, nor any of their employees, makes any warranty, express or implied, or assumes any legal liability or responsibility for the accuracy, completeness, or usefulness of any information, apparatus, product, or process disclosed, or represents that its use would not infringe privately owned rights. Reference herein to any specific commercial product, process, or service by trade name, trademark, manufacturer, or otherwise does not necessarily constitute or imply its endorsement, recommendation, or favoring by the United States Government or any agency thereof, or Battelle Memorial Institute. The views and opinions of authors expressed herein do not necessarily state or reflect those of the United States Government or any agency thereof.

\author{
PACIFIC NORTHWEST NATIONAL LABORATORY \\ operated by \\ BATTELLE \\ for the \\ UNITED STATES DEPARTMENT OF ENERGY \\ under Contract DE-AC06-76RLO 1830
}

Printed in the United States of America

Available to DOE and DOE contractors from the

Office of Scientific and Technical Information, P.O. Box 62, Oak Ridge, TN 37831;

prices available from (615) 576-8401.

Available to the public from the National Technical Information Service, U.S. Department of Commerce, 5285 Port Royal Rd., Springfield, VA 22161

This document was printed on recycled paper.

(9/97) 


\section{DISCLAIMER}

Portions of this document may be illegible in electronic image products. Images are produced from the best available original document. 


\section{Effects of Crust Ingestion on Mixer Pump Performance in Tank 241-SY-101: Workshop Results}

PA Meyer

CW Stewart

CE Brennen ${ }^{(a)}$

September 1999

Prepared for

the U.S. Department of Energy

under Contract DE-AC06-76RLO 1830

Pacific Northwest National Laboratory

Richland, Washington

(a) California Institute of Technology 


\section{Summary}

In August 1999, a workshop was held at Pacific Northwest National Laboratory to discuss the effects of crust ingestion on mixer pump performance in Hanford Waste Tank 241-SY-101. The main purpose of the workshop was to evaluate the potential for crust ingestion to degrade mixing and/or damage the mixer pump. The need for a previously determined 12-inch separation between the top of the mixer pump inlet and the crust base was evaluated. Participants included a representative from the pump manufacturer, an internationally known expert in centrifugal pump theory, Hanford scientists and engineers, and operational specialists representing relevant fields of expertise.

The workshop focused on developing an understanding of the pump design, addressing the physics of entrainment of solids and gases into the pump, and assessing the effects of solids and gases on pump performance. The major conclusions are summarized as follows:

- Entrainment of a moderate amount of solids or gas from the crust should not damage the pump or reduce its lifetime, though mixing effectiveness will be somewhat reduced.

- Air binding should not damage the pump. Vibrations due to ingestion of gas, solids, and objects potentially could cause radial loads that might reduce the lifetime of bearings and seals. However, significant damage would require extreme conditions not associated with the small bubbles, fine solids, and chunks of relatively weak material typical of the crust.

- The inlet duct extension opening, 235 inches from the tank bottom, should be considered the pump inlet, not the small gap at 262 inches.

- A suction vortex exists at the inlet of all pumps. The characteristics of the inlet suction vortex in the mixer pump are very hard to predict, but its effects likely extend upward several feet. Because of this, the current 12-inch limit should be replaced with criteria based on actual monitored pump performance. The most obvious criterion (in addition to current operational constraints) is to monitor discharge pressure and cease pump operation if it falls below a predetermined amount.

- There are no critically necessary tests to prove pump operability or performance before initiating the transfer and back-dilution sequence. 



\section{Contents}

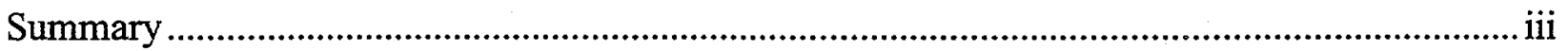

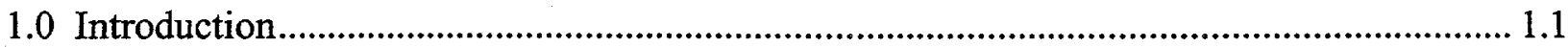

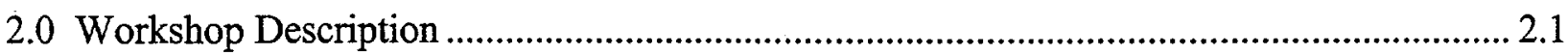

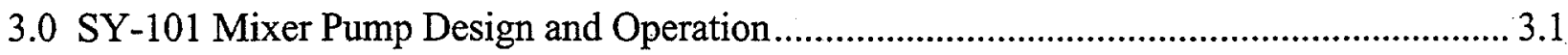

4.0 Effects of Crust Ingestion on Mixer Pump Performance................................................... 4.1

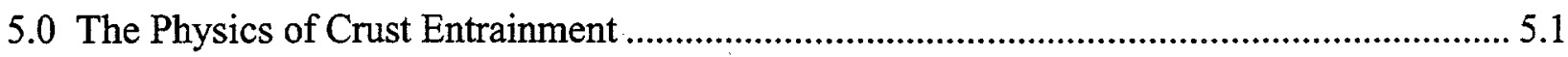

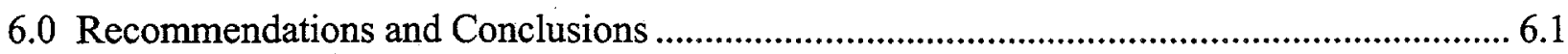

Appendix A: Workshop Participants ............................................................................. A.

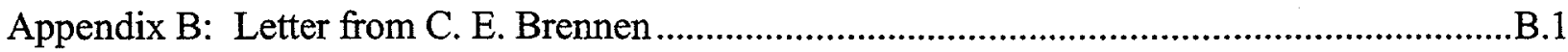

\section{Figures}

1.1 Crust Base Interfering with Mixer Pump Operation............................................... 1:1

3.1 Components of Mixer Pump System ................................................................................. 3.2

4.1 Performance Breakdown Due to Gas Ingestion in a Centrifugal Pump ............................ 4.1 


\subsection{Introduction}

The thick floating crust layer in Hanford Tank 241-SY-101 (SY-101) continues to be a safety concern. To reverse crust growth and reduce its retained gas volume, it is planned to dilute the waste in SY-101 by transferring a large fraction of the waste out of the tank and replacing it with water. The first step in the process is an initial transfer of approximately 100,000 gallons of mixed slurry in October 1999. The first back-dilution and subsequent transfers are planned to take place shortly after the initial transfer. Throughout this period of transfer and back-dilution sequences, the mixer pump must continue to operate to prevent formation of a deep nonconvective layer and the associated gas retention that could lead to large buoyant displacement gas releases.

However, there is a concern that the initial transfer could bring the base of the crust, now at approximately 310 inches, too close to the mixer pump upper inlet, which is at 262 inches. ${ }^{(a)}$ The pump could be damaged or might ingest high-void crust material and stop providing adequate mixing, as shown in Figure 1.1. Controls are in place to limit the transfer volume such that a 12inch margin will be maintained between the base of the crust and the top of the pump upper inlet. These controls are based on earlier analysis of the flow field near the pump upper inlet. ${ }^{(b)}$

It has become apparent recently that the 12-inch margin needs to be reevaluated. The crust base dropped from about 350 inches to about 300 inches during April and May 1999. Since then, it has stabilized at about 310 inches. The reason for this rapid growth is not well understood, and the possibility of a similar event prior to the initial transfer must be allowed for.
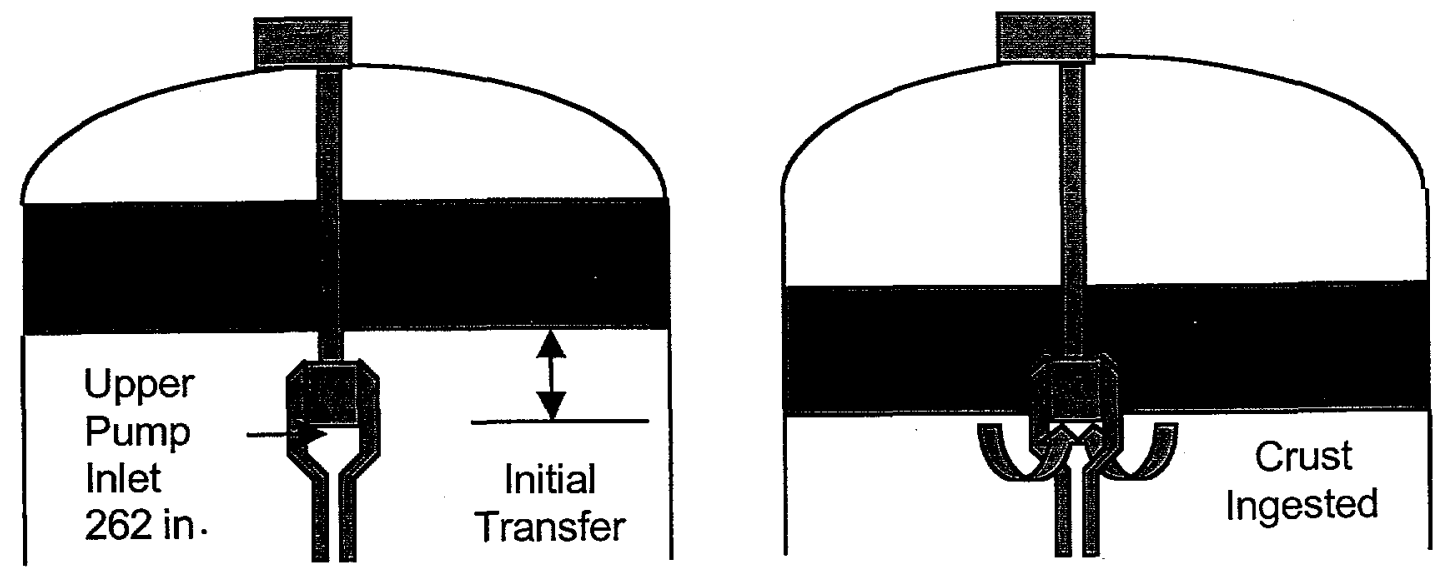

Figure 1.1. Crust Base Interfering with Mixer Pump Operation

(a) Raymond RE. August 18, 1999. Letter 79000-99-053 to SY-101 Project Group. "241-SY-101 Mixer Pump Inlet Level." Lockheed Martin Services Hanford, Richland, Washington.

(b) Meyer PA, CW Stewart, KP Recknagle, and Y Onishi. 1999. Minimum Elevation of the Base of the Crust Layer for Mixer Pump Operation in SY-101. PNNL Letter Report TWS99.28, Pacific Northwest National Laboratory, Richland, Washington. 
If the crust base were to drop again by a similar amount, even a small transfer would violate the 12-inch margin. In addition, the technical basis for the 12-inch margin needs to be revisited. The 12-inch separation was determined from a simplistic model that compared the shear stresses on the crust base induced by the pump inlet suction flow field with the assumed strength of the crust base material.

An expert workshop was held at Pacific Northwest National Laboratory on August 4, 5, and 10,1999 , to reexamine the 12 -inch separation control. Its purpose was to evaluate the potential for crust ingestion to degrade mixing and/or to damage the mixer pump. Attendees included experts in the following areas:

- Centrifugal pump design, theory, and operation

- Fluid mechanics, multiphase flow, mixing, sludge mobilization

- Thermal sciences, transport phenomena, heat transfer

- Flammable gas safety, nuclear safety and licensing

- Tank waste configuration and properties

- Tank farm and mixer pump operations

- Process Engineering

- Mechanical Design

- Electrical Engineering

In addition, engineers familiar with the specific design details of the mixer pump and a representative from the pump manufacturer were present. The workshop focused on the pump design, the physics of entrainment of solids and gases into the pump, and the effects of solids and gases on pump performance.

This report summarizes the information presented and discussed during the workshop and the major conclusions. Section 3 describes the structure of the workshop and presents the issues that were addressed. Sections 4-6 contain a summary of the information-gathering phase of the workshop: Section 4 addresses pump design and operation, Section 5 the effects of solids and gas on pump performance, and Section 6 the physics of crust entrainment. Section 7 presents the major conclusions and recommendations developed during the workshop. Appendix A lists the workshop participants, and Appendix B contains a letter of findings by Professor Christopher Brennen from the California Institute of Technology. 


\subsection{Workshop Description}

The workshop attempted to develop consensus-based, technically defensible answers to the following questions:

- Is the existing 12-inch separation requirement between the bottom of the crust and the top of the pump inlet sufficient to ensure effective mixer pump operation?

- Is 12-inch separation necessary, or is there a better alternative method to ensure effective mixer pump operation?

- Can the pump survive temporarily ingesting crust, or must crust ingestion be avoided altogether?

The format used to achieve answers to these questions involved identifying key questions, addressing essential issues, and capturing information in the form of questions, ideas, and conclusions.

It is important to carefully define what is meant by degraded pump operations and crust ingestion. For the purposes of the workshop discussion, these were defined as follows:

\section{Degraded Pump}

- Reduction in mixing efficiency due to the presence of solids or gas in the process stream. The net effect of reduced efficiency would be a reduction in pump discharge pressure resulting in less jet momentum and hence less mobilization of the settled solids layer.

- Reduction in allowable pump operating time. Because operating time is limited by oil temperature, degraded cooling due to gas ingestion would result in a decrease in operating time. This also would reduce mobilization of settled solids because it is dependent, to some extent, on mixer pump run time.

- Permanent damage to the pump or operational difficulties requiring disruption of normal pump operating procedures.

\section{Mixer Pump Effectiveness:}

The ability of the mixer pump to mitigate buoyant displacement GREs by adequately preventing the buildup of a nonconvective layer at the bottom of the tank.

\section{Crust Ingestion}

Entrainment of solids, bubbles, or bulk material (matrix of gas/liquid/solid) into the mixer pump inlet. This could also include ingestion of foreign materials. The following key questions were identified and addressed extensively during the workshop:

- Under what conditions is crust ingestion likely?

- What will be the effects of crust ingestion on mixer pump effectiveness? 
- What separation is required to maintain effective mixer pump operation?

- Are lab-scale or full-scale tests required?

- Are there monitoring activities, operational approaches, or response actions that will help maintain effective mixer pump operation?

- Are there other issues to be considered?

The following technical categories were used as working issues throughout workshop discussions:

- Air Binding. This relates to the trapping or accumulation of gas in the mixer pump. Accumulation of solids was also considered.

- Performance Breakdown. This refers to hydrodynamic breakdown across the pump impeller resulting in performance degradation.

- Heat Transfer. This relates to reduction in motor cooling resulting from entrained crust material.

- Entrainment. This refers to the process, external to the pump, whereby crust material is ingested into the pump. 


\subsection{SY-101 Mixer Pump Design and Operation}

Figure 3.1 is a schematic of the relevant components of the mixer pump. The waste enters the inlet, passes through the impeller, and then enters the volute. Rather than being discharged, the waste enters the annular cooling jacket around the oil-filled motor casing by way of two large crossovers. After performing its cooling function in the annular jacket, the waste is discharged through the nozzles.

A tailpipe, or inlet duct extension, was added as a structural member to prevent the pump column breaking during installation. It is 235 inches from the tank bottom and has no hydraulic function. A small gap exists between the tail pipe and the upper pump inlet. The original 12inch separation was measured from the top of this gap (262 inches from the bottom of the tank) to the crust base. The gap is severely obstructed by bolt blocks. There is no hydraulic reason for the small gap; it was provided to prevent forces on the wearing ring at the pump inlet. There are twin discharge volutes, each with its own crossover. The cooling jacket is a common plenum for both volute discharge streams. The motor stator and rotor are immersed in oil, which swirls around the casing by rotation of the rotor and shaft. There is no way to add additional oil. Asbuilt elevations from the tank bottom are available for all the major components of the pump.

The pump was originally designed for short-term operation (two-year design life). It has now operated six years. The primary catastrophic failure mode is oil loss through the seals. The pump has both inboard and outboard seals; both need to fail in order to lose oil. Seal failure would be accelerated by vibrations induced by bearing wear. The oil lifetime is estimated to be about 20 years in the SY-101 radiation environment. The oil temperature limit is stated as $210^{\circ} \mathrm{F}$ by the pump manufacturer. The temperature is limited operationally to $190^{\circ} \mathrm{F}$. One study of seal life determined that lifetime of seals is $9 \pm 3$ years. Temperature effects are deemed more important than radiation dose with regard to seal life. Thermal cycling effects on seal life have not been studied.

There are places where water can be introduced into the mixer pump system: a burrowing ring below the discharge nozzles that can inject about 30 gpm vertically downward and a highpressure heel-flush port in the nozzles that operates at very low flow rate. A suction clearing ring introduces water into the bell mouth at about $30 \mathrm{gpm}$. The annular jacket flush was designed to decontaminate the pump internals prior to removal. The flush line is attached to a 2inch ring header that has four 1-inch lines entering the annular jacket; the annular jacket flush can operate at about $140 \mathrm{gpm}$. The ring header has one 3/16-inch-diameter hole that was designed to bleed trapped air out of the pump during installation. It is not known whether this hole is now plugged with waste. The ring header sees pump discharge pressure at all times during pump operation so it is possible that the hole is clear. The annular jacket flush would probably not flush the entire rotor/inlet because the passages between impeller blades are quite large and the water would likely find a preferred path. The annular jacket was flushed twice during May 1999 with no measurable effect on pump monitoring data. 


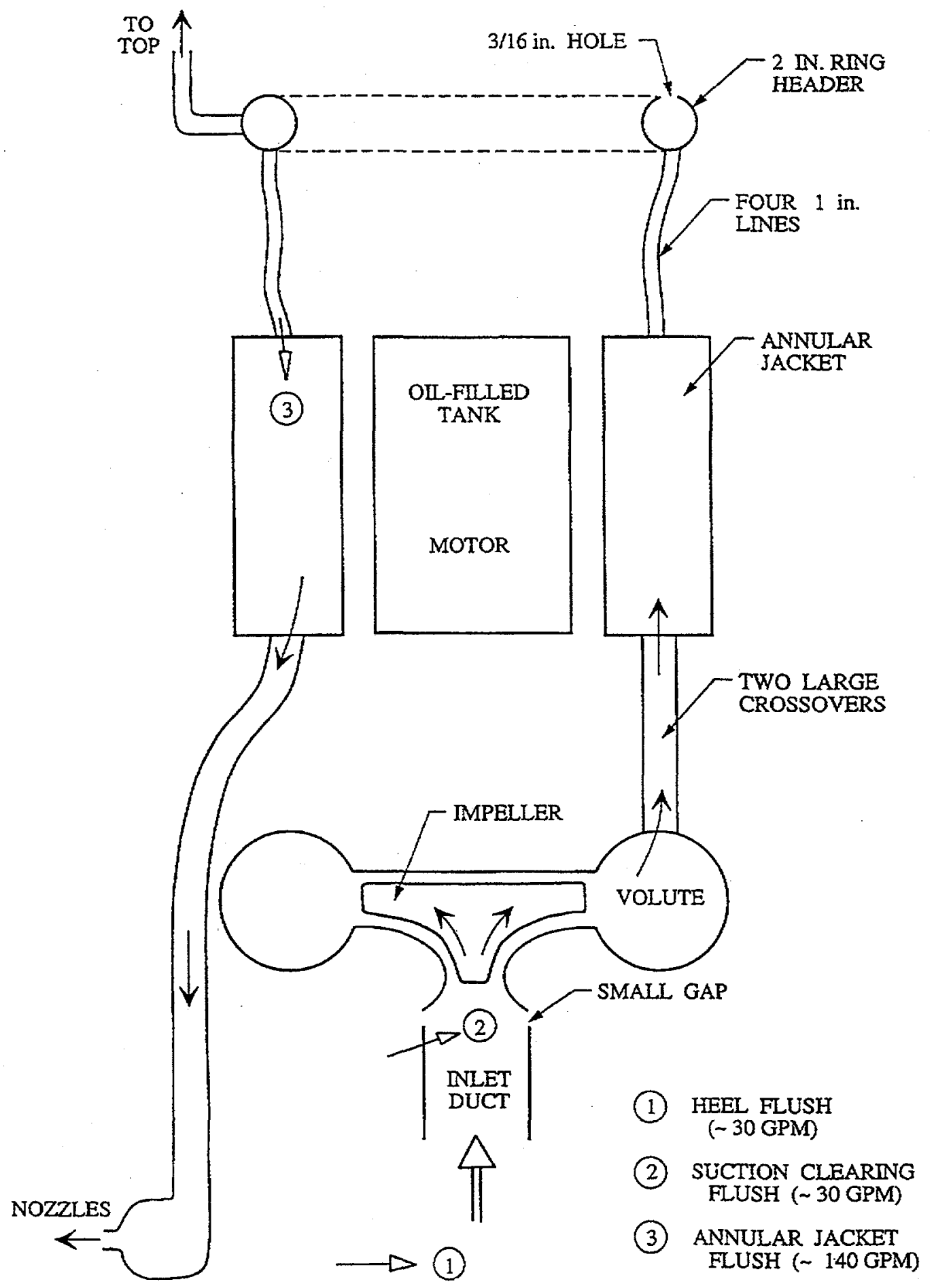

Figure 3.1. Components of Mixer Pump System 
The following operational shutdown criteria and alarms are specified for the pump:

- Motor current 1.4 times expected amps, alarm at 1.2

- Motor oil temperature at $225^{\circ} \mathrm{F}$, alarm and shutdown at $190^{\circ} \mathrm{F}$

- Motor oil moisture indication (conductivity sensor)

- Pump column strain gauge at 194 micro-inch/inch

- Pump column gas pressure $7 \mathrm{psig}$, alarm at 9 psig

- Discharge pressure operating limit.

The primary indication of nozzle plugging or entrainment of solids or gas would be changes in nozzle discharge pressure. The motor oil temperature generally reaches $190^{\circ} \mathrm{F}$ in about 25 minutes of operation. During pre-installation testing in water, the pump could operate indefinitely without reaching $190^{\circ} \mathrm{F}$. The reason for the higher temperatures in the tank is thought to be the larger current required to pump waste with a much higher specific gravity and viscosity than water. 


\subsection{Effects of Crust Ingestion on Mixer Pump Performance}

Pump degradation due to crust ingestion can result from either entrained gas or solids. Degradation due to entrained gas can come from either performance breakdown or air binding. Breakdown occurs at the impeller and volute. Entrained gas bubbles form a gas-filled wake on the suction side of impeller blades, causing substantial departure from design performance. Breakdown is not to be confused with cavitation. Unlike cavitation, breakdown will not damage the impeller.

Figure 5.1 shows a representative relationship between discharge pressure and void fraction. For low void fraction, the effect is minor and can be attributed primarily to a reduction in bulk density of the waste (pump head remains constant in this range). As the void fraction is increased, a relatively dramatic decrease in discharge pressure occurs. The precise void fraction where this occurs depends on a number of factors, including fluid viscosity, bubble size, surface tension, pump specific speed, and pump size. The typical range for centrifugal pumps is 10 $20 \%$. Axial flow pumps can experience breakdown at as low as $8 \%$ void fraction.

Because breakdown depends on a large number of parameters, determining where it will occur for the mixer pump is impossible without full-scale testing. Bubble size is very important; small bubbles are transported through the impeller without forming large voids. Also, shear stresses at the inlet tend to break larger bubbles into smaller ones. Breakdown should not limit the ability of the mixer pump to operate. If breakdown occurs, the pump can be shut down and the gas will clear, allowing restart. Severe breakdown due to ingestion of large voids can produce axial force imbalances on the impeller blades. Prolonged operation under these conditions can lead to bearing and seal damage.

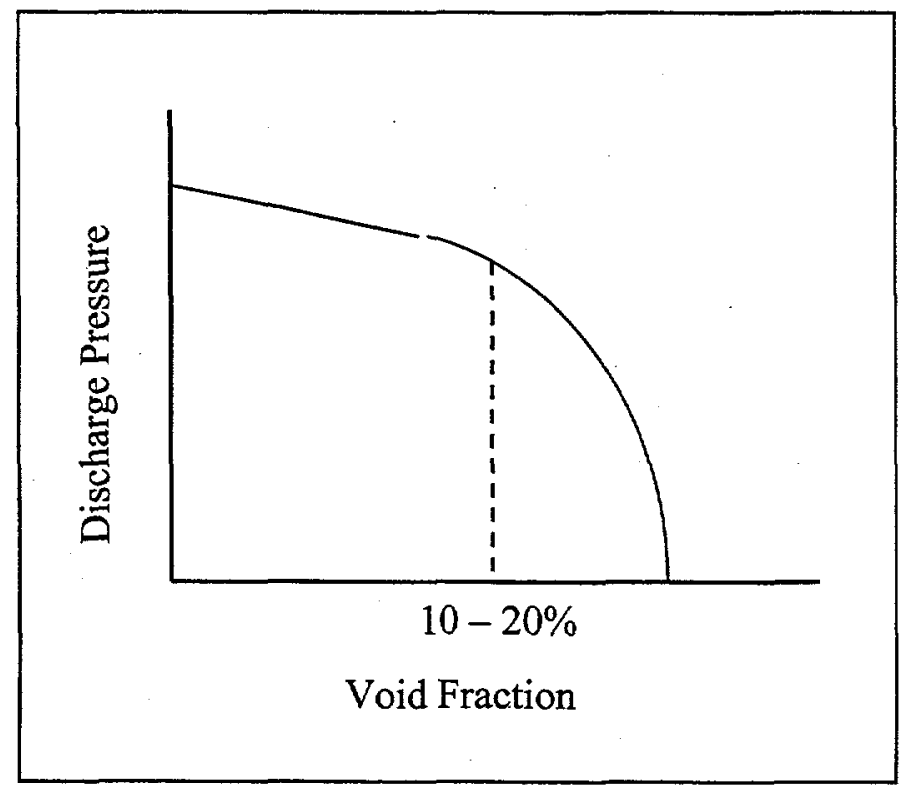

Figure 4.1. Performance Breakdown Due to Gas Ingestion in a Centrifugal Pump 
Air binding occurs when a pocket of gas is of trapped in the pump internals. Air binding occurring at the impeller is similar to the performance breakdown phenomena. However, if the impeller is air-bound, the pump cannot be started because the blades are not contacting any fluid. This type of air binding would not be possible for the mixer pump unless the entire inlet, volute, and cooling jacket were intentionally air-filled. This would have been nearly the situation upon initial pump installation and was the reason for adding the small hole in the ring header. A more likely gas buildup scenario could occur in the annular cooling jacket, which provides a separation chamber for the gas voids in the waste that are processed by the pump. The degree of gas buildup depends on inlet void fraction, and the amount of flow (if any) through the small hole in the ring header will also affect the buildup of gas. An as-yet undetermined amount of gas buildup in the cooling jacket is certain to occur. The primary effect of air binding or gas buildup in the annular cooling jacket would be reduction in motor cooling. This would result in faster oil temperature heatup and a shorter run time.

Entrained solids can have several effects on mixer pump performance. Fine solids, which are carried with the fluid, will increase the bulk specific gravity, which requires additional power to pump. This would cause the pump to draw additional current, resulting in faster oil temperature heatup and reduced run time. Solids could also build up in the annular cooling jacket, which could act like a settling chamber. As with accumulation of gas, the degree of settling in the cooling jacket would depend on solids fraction, waste physical properties, solids settling times, fluid residence time in the annular jacket, and the degree of turbulence. The primary effect of solids buildup in the cooling jacket would be degraded cooling due to loss of heat transfer contact area between the liquid waste and the motor casing. The annular jacket flush operation should clear any settled solids.

Finally, if large chunks of hard solids or foreign objects enter the mixer pump, impact with the impeller blades would result in sudden load imbalances that could damage the bearings. This is not thought to be a major concern in SY-101 for two reasons. First, it is very unlikely that foreign objects are lodged in the lower region of the crust. The base of the crust is newly formed, and foreign objects likely would have sunk to the bottom of the tank during violent rollovers before the mixer pump was installed. Second, the crust base material is believed to be relatively weak. The impact of a discrete portion of this material with the impeller blade is analogous to a week ball of mud hitting a wall. The likelihood of material with high strength being liberated from the crust and ingested is considered very unlikely. Additionally, the main inlet is oriented downward. The upward velocities near the inlet are insufficient to entrain substantial sized debris. 


\subsection{The Physics of Crust Entrainment}

The degree to which the crust material will be ingested into the mixer pump depends on the nature of the inlet vortex and its interaction with the crust base. An inlet vortex always forms at the inlet of a submerged pump. Because the vorticity is essentially conserved, the vortex must terminate at a surface. A vortex from a pump submerged in a liquid with a free surface will often entrain air, or ventilate. Significant performance degradation generally occurs when the inlet vortex ventilates because air is drawn directly into the inlet. Whether the vortex ventilates depends on several factors. The submergence of the inlet is important. The smaller the submergence, the more likely ventilation will occur. The critical submergence (the submergence at which the vortex cannot ventilate) scales roughly with the inlet diameter. Inlet vortices as much as $8-10$ diameters below the surface may ventilate. The critical submergence also depends on the vortex strength. The strength of an inlet vortex is design-dependent. However, as a rule, the strength will be minimized when the pump is operating at its design flow rate. As the flow rate is reduced, the inlet vortex becomes stronger. Pumps operating at very low flow rate will have the strongest inlet vortices. The mixer pump in SY-101, when operating at $1000 \mathrm{rpm}$, is operating at just below its design flow rate. This means the inlet vortices are not as strong as they could be; however, there is no way of knowing how strong they actually are without fullscale testing.

Solid surfaces such as sheets of floating plywood can be used to prevent vortex ventilation. Therefore, the 10-foot-thick crust in SY-101 should effectively eliminate vortex ventilation. However, little is known about the interaction of inlet vortices with a weak solid surface such as the crust base. It is reasonable to assume that the inlet vortices have, to some degree, already eaten away some of the crust base near the pump. Because the pump is operating close to its design point, the vortex will not be strong enough to ventilate until the base of crust gets near the inlet. Even then, ventilation would be impossible unless there is abundant gas available. Unless the vortex ventilates, it probably cannot pull enough bubbly material into the inlet to cause a problem. The downward velocity inside the vortex core is probably not much greater than the downward velocity away from the vortex. To be conservative, however, it is best to assume that the vortex will pull some small amount of crust gas into the pump.

The chance of inlet plugging due to crust entrainment is very slight. The lowest part of the crust is likely quite slushy, as observed during operation of the mechanical mitigation arm in late May, and therefore should not plug. The impeller will break up small chunks of crust material. Any large chunks of crust would be filtered out by hardware surrounding the main inlet. Additionally, the crust material, which is strong enough to plug the inlet, is unlikely to break away from the crust and get into the pump by virtue of its own strength. If inlet plugging were to occur, it would be immediately detectable from discharge pressure or motor amperage. 


\subsection{Recommendations and Conclusions}

Throughout the workshop, whenever a consensus on an important issue was reached it was captured as a conclusion or recommendation. These are summarized as follows:

1. Gas entrainment into the small gap is not a concern because the majority of the flow enters the pump through the main inlet. For all practical purposes, the gap does not act as an inlet. The original 12-inch separation was based on the distance between the crust base and the small gap. It is more meaningful to consider the distance between the crust base and the main inlet. The main inlet elevation is 235 inches from the tank bottom; the small gap is 262 inches from the bottom.

2. Entrainment of a moderate amount of solids or gas from the newly formed lower region of the crust does not significantly damage the pump or reduce its lifetime, though mixing effectiveness would be somewhat reduced.

3. Pump performance degradation is not equivalent to pump damage. For small void fractions, degradation means reduction in discharge pressure, which is, from a hydraulic point of view, equivalent to operating the pump at lower speed. Degradation can eventually lead to pump damage if it is severe enough and continues for an extended period of operation measured in hours.

4. There will be obvious and adequate precursors to pump damage by performance degradation. Discharge pressure will be significantly reduced and oil heatup rate will significantly increase.

5. Air binding should not damage the pump. Vibrations due to ingestion of air/solids/objects potentially could cause radial loads that might reduce the lifetime of the bearings and seals. However, this would require extreme conditions not associated with small bubbles, fine solids, and weak chunks.

6. The pump has operated for about 500 hours since installation and thus is very young in terms of the normal operating lifetime for similar pumps.

7. Bearing failure leading to seal damage is the primary failure mode of the pump. Bearing failure would not occur suddenly even under extreme conditions. Failure would generally take several hours, not minutes.

8. There has always been some gas in the mixed slurry. Hence, technically speaking, the pump has been operating in a somewhat degraded mode all along. Recent changes in slurry void fraction have been readily apparent in discharge pressure.

9. The process of transfer and back-dilution does not increase the risk of ingestion of foreign object debris (FOD). The lower portion of the crust has been recently formed, so there is little reason to suspect FOD would be embedded in it. 
10. The characteristics of the inlet suction vortex are very hard to predict but can be assumed to affect the base of the crust. Because of this, the 12-inch limit is ineffective and should be replaced with criteria based on monitored pump performance. The most obvious criterion is to monitor discharge pressure and stop pump operation if it falls below a predetermined amount.

11. The minimum allowable discharge pressure for pump operation should be based on analysis of the mobilization and mixing of settled solids in the tank.

12. If pump performance measures deviate from the norm, then operation should cease pending evaluation. There is no need to develop a detailed degraded pump operating criteria before the fact.

13. It is not necessary to run the pump as often as in the past during an ongoing transfer and back-dilution campaign because the potential for serious buoyant displacement GREs will be eliminated before a dangerous amount of gas can accumulate. Therefore, if significant degradation occurs during operation, the frequency of operation can be reduced. The reduced frequency should depend on analysis of gas generation and rate of retention.

14. There are no critically necessary tests to perform before the transfer and back-dilution steps are initiated. Even though they are not necessary, several potential tests have been identified:

- Inject air into the inlet flush jets to assess the effect of air ingestion. The potential value would be to demonstrate that the pump could operate with significant gas entrainment.

- Perform scaled tests to assess vortex formation under a crust and the effect of vortices on a crust.

- Monitor thermocouple uncovery at several different pump speeds and correlate waste mobilization with discharge pressure. This could verify experimentally the minimum allowable discharge pressure.

- Pump water down the annular jacket flush during pump operation and see if oil heats up more slowly. This would help determine whether some air holdup is occurring in the annulus. 
Appendix A

Workshop Participants 


\section{Appendix A: Workshop Participants}

Name

JR Biggs

JM Grigsby

CE Hanson

CP Shaw

FA Schmorde

GJ Gauck

GD Johnson

NW Kirch

RE Raymond

FF Erian

ZA Antoniak

PA Meyer

WL Kuhn

CW Stewart

W Haentjens

CE Brennen
Area of Expertise

Tank Farm Operations

Nuclear Safety \& Licensing

Mechanical Engineering Design

Pump Design

Tank Farm Operations

Plant Engineering

Flammable Gas Safety

Process Engineering

Electrical Engineering

Multiphase Flow

Heat Transfer

Fluid Mechanics

Transport Phenomena

Thermal Fluids Science

Centrifugal Pumps

Centrifugal Pumps

\section{Organization}

E2 Consulting Engineers Inc G\&P Consultants Inc

Cogema Engineering Corp

Cogema Engineering Corp

Lockheed Martin Hanford Corp

Lockheed Martin Hanford Corp

Lockheed Martin Hanford Corp

Lockheed Martin Hanford Corp

Lockheed Martin Hanford Corp

Pacific Northwest National Laboratory

Pacific Northwest National Laboratory

Pacific Northwest National Laboratory

Pacific Northwest National Laboratory

Pacific Northwest National Laboratory

Hazleton Pump Co

California Inst. of Technology 
Appendix B

Letter from Christopher Brennen 
360 Olive Tree Lane

Sierra Madre, Cal. 91024

August 17,1999

Perry Meyer

Fluid Dynanics Group

Pacific Northwest National Laboral.ory

Report on Aug.4, 5, 1999, Visit

by

Christopher E. Brennen

California Institute of Technology,

Pasadena, CA 91125

\section{Purpose}

The purpose of my consultming visit to Hanford. hosted by the Fluid Dynamics Group, Pacific Northwest National Laboratory, was to advise r.hem on issues pertaining to how the mixer pumj in the 101 waste tank would perform upon ingestion of crust. On the first day I visited with Perry Meyer. Zen Antoniak. Charles Stewart and Craig Shaw for an orientation on the waste tank and the mixer pump. On the second we transitioned into a workshop with many additional participants to study the issues in detail.

\section{Summary}

In general. these experiences led me to conclude that the stafi are addressing the complex scientific and engineering issues of mixer pump crust ingestion in a thorough, constructive and realistic manner. I believe I was able to add something to the discussion as a result of my previous experience in a wide variety of pump problems and multiphase flow issues. The interactive discussions at the pump workshop were particularly constructive and resulted in a number of specific technical directives and conclusions which were summarized in a report. which was prepared during the workshop (it is currently only available to me in rough form but the essence of each point is clear). Each of these comments and conclusions was reached after careful discussion which incorporated comments from many perspectives. I agreeded with all of the comments and conclusions and believe they form a sound basis for a re-examination of the waste removal strategies.

It would therefore not be particularly valuable for this report to re-iterate all of the detailed discussion which led to the conclusions in the report since 1 
regard that report as, in effect, constituting part of my report. However, it miay: be valuable to re-iterate a few basic issues to which I contributed in a substantial way.

\section{Some Specific Issues}

- In my experience it is of critical importance in any turbomachinery issue to take the time to fully understand the complicated geometry of the device in question. Thanks to Craig Shaw we did this in this case and, as a result, several new perspectives emerged. I continue to urge attention to the details of the mechanies and fiuid dynamics of the mixer pump and its principal components, namely the induction motor in its oil-filled cavity, the bearings, the seals, the cover gas, the annular waste-fiuid-filled jacket around the oil cavity, the double volute and the impeller in addition to the components modified or added for use in SY-101, namely the inlet duct. the downcomers and the nozzles. A rough schematic of these components is attached.

- I continue to recommend that the pump manufacturer be pressed to provide as much knowledge as they have on the performance of this pump and experiences with the pump in the field. It would be my judgement that the pump is most likely to fail because the seal at the bottom of the oil-cavity begins to leak and the oil is lost. Since there is no way to replenish the oil this will mean the end of the pump as an operable unit. It is important. to emphasize that it is only a question of time until this happens. Consequently any field experience with these pumps which the manufacturer could provide would be valuable in evaluating the possible failure modes and, perhaps, devising ways to extend the pump life.

- It is also important to emphasize that this is a rugged sump pump designed to ingest alot of solids and, perhaps, gases without signicant damage. Incleed the mixer pump may well have ingested substantial solids during the initial mixing during Phase $B$ tests. It seems to me quite unlikely that ingestion of crust material, particularly from the bottom of the crust, is likely to cause much harm to the pump impeller or volute.

- During our discussions, I indicated that the accumulation of gas in the annular cooling jacket (the high point of the waste flow route) was a more likely cause for concern. Perhaps the accumulation of gas in this space has always caused a decrease in the leat transfer from the oil-filled cavity and therefore the unexpectedly high rate of temperature increase in the oil during pump runs. This would be a concern if future use ingested greater volume fractions of gas and resulted in even more gas accummulation in the annular jacket - leading to shorter pump runs due to shut down at the red-lined oil temperature. 
- The fluid mechanics of gas ingestion were also discussed at length and I introduced the concept of intake vortex ventilation which had not been recognized by the group. In the case of water intakes (for example to power plant cooling systems) this phenomena determines the minimum submergence at which the intake can be operated. Extensive literature exists on this subject. However, I know of little experience which applies when there is a floating crust on top of the liquid. I suspect that the vortex will still form (its strength increases as the pump operating point. is lowered below the design point) and will impinge on the bottom of the crust layer. But there is little to guide us on the submergence at winich the vortex could begin to ingest solids/gases from the crust which would then travel down the vortex core into the pump inlet. This could happen even if the clearance between the pump suction and the crust bottom were several suction diameters. I recommend that some basic research program be conducted at a model scale to identify the phenomena that occur with a floating crust. Quantitatively the results might be difficult to scale up to prototype size; however qualitatively it would be of value to know what the basic fluid dyaamic processes are. For example, it might be valuable to determine whether the intake vortex might in fact help by scouring and eating away at the bottom of the crust in the vicinity of the pump. In my view the issues with respect to the behavior of the intake are the least predictable of the central issues in question.

- In the light of the above uncertainities, it is not clear 10 me that the current 12inch clearance constraint makes nuch sense. I do think that monitoring the pump head and placing a constraint on the amount of head degradation to be tolerated is much more sensible. One suggestion might be to establish an alarm at, say, 10/drop and an autornatic shutdown at 40/maintain some elevation clearance in addition. Since I do not believe that any solids or gases ingested through the "small gap" at the original suction bellmouth could cause a problem, a prudent additional constraint might be to maintain some minimum clearance between the bottom of the suction duct and the bottom of the crust - say one diameter of the suction duct. Of course, throughout it is critical to maintain the current limits on oil temperature and motor amps.

I emplasize that these are only a few of the issues which are covered in the pump workshop report which should be appended to this letter report.

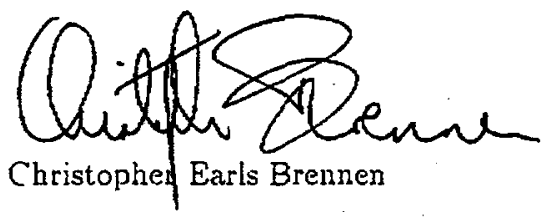


PNNL-13139

UC-2030

\section{Distribution}

No. of

Copies

\section{Offsite}

2 Office of Scientific and Technical Information

C. E. Brennan 360 Olive Tree Lane Sierry Madre, CA 91024

\section{Onsite}

17 PHMC Team

W. B. Barton

R2-11

R. E. Bauer (3)

J. R. Biggs

R. J. Cash

J. M. Grigsby (3)

B. K. Hampton

C.E. Hanson

G. D. Johnson

N. W: Kirch

L. J. Kripps

R. E. Raymond

C.P. Shaw

F. A. Schmorde
S7-07

S7-73

R1-44

G1-24

S7-70

S7-73

R2-11

S7-73

S7-70

R3-74

T4-08
No. of

Copies

3 DOE Richland Operations Office

C. A. Groendyke (3)

H6-60

19 Pacific Northwest National Laboratory

J. M. Bates

K7-15

S. Q. Bennett

K7-90

J. W. Brothers (4)

K9-20

C. E. Enderlin

K7-15

W. L. Kuhn

K7-15

P. A. Meyer (2)

K7-15

C. W. Stewart (3)

K7-15

B. E. Wells

K7-15

Information Release (5)

Distr. 1 